\title{
Application of neutral electrolyzed water to disinfection of alginate impression
}

\author{
Yuki NAGAMATSU1 ${ }^{1}$, Ker-Kong CHEN², Hiroshi NAGAMATSU³, Yoshio KOZONO¹ and Hiroshi SHIMIZU1 \\ ${ }^{1}$ Division of Biomaterials, Department of Oral Functions, Kyushu Dental University, 2-6-1 Manazuru, Kokurakita, Kitakyushu 803-8580, Japan \\ ${ }^{2}$ Department of Conservative Dentistry, School of Dentistry, College of Dental Medicine, Kaohsiung Medical University, 100 Shih-Chuan 1st Road, \\ San-Ming District, Kaohsiung, 807, Taiwan \\ ${ }^{3}$ Division of Comprehensive Dentistry, Department of Oral Functions, Kyushu Dental University, 2-6-1 Manazuru, Kokurakita, Kitakyushu 803-8580, \\ Japan \\ Corresponding author, Yuki NAGAMATSU; E-mail: yuki-naga@kyu-dent.ac.jp
}

\begin{abstract}
Neutral electrolyzed water was developed with new concepts of long-term good durability and minimum corrosiveness to metal in addition to its excellent bactericidal activities similar to acid type of electrolyzed waters. The present study examined the bactericidal effects of the neutral electrolyzed water on disinfection of the alginate impression of a dental arch model contaminated by bacteria. Only 1-min immersion in neutral electrolyzed water could sufficiently disinfect the alginate impression including the metallic tray under ultrasonic with no significant differences from acid electrolyzed waters. No bactericidal effects were found in any electrolyzed water when used as mixing water. Considering the advantages and disadvantages of each electrolyzed water in a comprehensive way, it was suggested that neutral electrolyzed water may be the most appropriate for the disinfection of alginate impression.
\end{abstract}

Keywords: Neutral electrolyzed water, Hypochlorous acid electrolyzed water, Disinfection, Alginate impression, Impression tray

\section{INTRODUCTION}

With increasing in serious infectious diseases, various provisions against nosocomial infection have been taken in medical institutions ${ }^{1-10)}$. In dental practice, disinfection treatments such as immersion in disinfectant chemical solution, autoclaving and irradiation with UV light have been so far commonly carried out ${ }^{5-9)}$.

Especially the secondary infection by saliva, blood or gingival crevicular fluid through the impression of infected patient has been gaining great attention in dental practice. As one of the disinfection measures, the impression should be completely disinfected immediately after it is taken. Nakamoto et al. ${ }^{10)}$ reported that disinfection treatment of all the alginate impressions was made in $1.9 \%$ out of 53 dental offices surveyed in 1991 and $7.5 \%$ out of 41 in 1993 . They also reported that about $60 \%$ of dental offices have performed only washing treatment with tap water in both years ${ }^{10)}$. Shima and Fujihara ${ }^{11)}$ reported that $68.8 \%$ of 96 dental workers surveyed in 2001 washed the impression with tap water and $9.5 \%$ immersed it in disinfectant chemical solution. According to the 2009 questionnaire by Motegi et al. ${ }^{12)}, 34 \%$ of 934 dental offices disinfected impressions. Although the rate of disinfection treatment of impression has gradually increased in the last 20 years, further necessity of prevailing disinfection is emphasized ${ }^{13,14)}$.

Immersion treatments of impression in disinfectant chemical solutions such as sodium hypochlorite and glutaraldehyde have been mainly practiced and those solutions have also been recommended as useful media by the Japan Prosthodontic Society ${ }^{14)}$. However, the treatment requires 15-60 min immersion of impression in the solution. The authors previously reported that during such long immersion periods of alginate impression caused dimensional change inducing markedly distorted dental arch stone cast ${ }^{15)}$.

Disinfection with hypochlorous acid electrolyzed water (abbreviated as electrolyzed water in the present article) has been recently highlighted. Several types of electrolyzed waters are now available, including strongly acidic (pH: 2.2-2.7), weakly acidic (pH: 2.7$5.0)$, slightly acidic ( $\mathrm{pH}: 5.0-6.5)$ and neutral waters (pH: 7) (abbreviated strong acid water, weak acid water, slight acid water and neutral water, respectively). Above all, the strong acid water was first developed and has been long applied effectively in many fields such as industry ${ }^{16)}$, agriculture ${ }^{17)}$, foods ${ }^{18)}$, and stock breeding ${ }^{199}$. It was belatedly introduced and spread widely in medical and dental practices because of its rapid and certain sterilizing and disinfecting effects and besides harmlessness against vital biological tissues ${ }^{20)}$.

The authors first proposed the application of the strong acid water to the immersion treatment for disinfection of impression as an alternative to chemical solutions. The electrolyzed water is characterized by its rapid and strong bactericidal activity and besides least harmfulness to vital biological tissues. It was demonstrated that the complete disinfection of impression of simple flat surface could be attained by only 1 min immersion in this water ${ }^{21}$. On account of shorter treatment time, it caused no detectable distortion and surface roughness to the stone cast ${ }^{222}$.

The weak acid water, slight acid water and neutral water were developed afterwards. They have excellent bactericidal activities equally to the strong acid water and unfavorable characteristics of the strong acid water such as corrosiveness to metals and shorter durability of bactericidal activity were markedly improved with the increase in $\mathrm{pH}$ value ${ }^{23)}$. The authors have been much 
interested in the neutral water regarded as the safest sterilizing medium and developed its applicability to clinical dentistry ${ }^{24-27)}$.

The present study examined the bactericidal effect of neutral water for alginate impression comparing with those of other electrolyzed waters.

\section{MATERIALS AND METHODS}

\section{Preparation of electrolyzed waters}

Three types of electrolyzed water were used in this study. They were strong acid water (SW), slight acid water (WW), neutral water (NW) and tap water (TW) for comparison as shown in Table 1. SW was prepared by electrolyzing $0.05 \%$ sodium chloride (first-grade, Wako Pure Chemical Industries, Osaka, Japan) aqueous solution with a diaphragm by an electrolyzing apparatus (SUPER WATER mini, Hirata, Osaka, Japan). WW was prepared by electrolyzing tap water containing a specified electrolyte without a diaphragm by an automatic apparatus (ACIDENT, J. Morita Tokyo MFG, Tokyo, Japan). NW was also automatically prepared using tap water containing $5 \%$ sodium chloride. It is obtained through two steps of electrolyzation using $5 \%$ sodium chloride aqueous solution, first without and second with a diaphragm (APaqua21, Asahipretec, Kobe, Japan). Because the residual chlorine concentration in the resultant waters changes with time by light- or airexposure, these test waters were used for experiment within 1-h storage in sealed and shaded tank after preparation.

The $\mathrm{pH}$ value and oxidation-reduction potential (ORP) were examined with a $\mathrm{pH}$ meter (PHL-20, DKKTOA, Tokyo, Japan). The concentration of residual chlorine was determined with a chlorine comparator (DPD, Shibata Scientific Technology, Saitama, Japan) based on the DPD method.

\section{Bactericidal test}

Flow charts of all bactericidal tests conducted in this study are shown in Fig. 1. As a fundamental study, the bacteria used were Staphylococcus aureus NBRC12732, which have been commonly used for evaluating bactericidal effects. The bacteria was incubated in a brain heart infusion (BHI, DIFCO, Detroit, MI, USA) at $37^{\circ} \mathrm{C}$ for $24 \mathrm{~h}$. Bacteria suspension was prepared to be $5.0 \times 10^{7} / \mathrm{mL}$ in BHI.

The procedures of three experiments for the impression (EX1, EX2 and EX3) are shown in Figs. 1 (a), (b) and (c). A plastic model (Dentulous maxilla 500A type, Nissin Dental Products, Kyoto, Japan) was immersed in $500 \mathrm{~mL}$ bacteria suspension $\left(5.0 \times 10^{7} / \mathrm{mL}\right.$ in $\mathrm{BHI})$ for $10 \mathrm{~min}$. The impression of the model was taken with an alginate impression material (AROMA FINE DF III, NORMAL SET, GC, Tokyo, Japan) with the tray according to the manufacturer's recommendation. A steel tray coated with nylon resin (Abe impression tray Hi-flex AC, Tokyo shizaisha, Tokyo, Japan) shown in Fig. 2 was used after cleaning in methanol (specialgrade, Wako Pure Chemical Industries) using an ultrasonic cleaner (VS-150, AS ONE, Osaka, Japan) and autoclaved in this study. In EX1 shown in Fig. 1(a), the impression with tray, which was contaminated with the level of $10^{6}$ to $10^{7}$ bacteria after taking, was immersed in $500 \mathrm{~mL}$ of the test water shown in Table 1 with or without ultrasound. After treatment and shaking down the suspension, the surviving bacteria numbers on two surfaces, areas of palate and anterior edge (Fig. 3), were also examined partially using the samples which were collected by wiping $1 \mathrm{~cm}^{2}$ of their surfaces with a sterile cotton swab (Nissui, Nissui Pharmaceurical, Tokyo, Japan). After wiping, the sample collected with the cotton swab was spread over an agar plate, or ultrasonically cleaned in $10 \mathrm{~mL}$ of sterile saline solution (OTSUKA PHARMACEUTICAL, Tokyo, Japan) for $30 \mathrm{~s}$ and 0.1 $\mathrm{mL}$ from the extract solution was added to the agar culturing medium. Each total number of the surviving bacteria sampled from the two areas was calculated from the number of the colonies in the medium after incubation at $37^{\circ} \mathrm{C}$ for $24 \mathrm{~h}$.

In EX2 shown in Fig. 1(b), the impression with tray after taking and treated with $500 \mathrm{~mL}$ of the test

Table 1 Properties of electrolyzed waters and tap water used in this study

\begin{tabular}{lcccc}
\hline Test water & Code & $\mathrm{pH}$ & ORP $(\mathrm{mV})$ & Residual chlorine (ppm) \\
\hline Electrolyzed water & & & & \\
Strong acid water & & & & \\
Slightly acid water $^{2}$ & $\mathrm{SW}$ & $2.4(0.04)$ & $+1,132(5.7)$ & $45(5.7)$ \\
Neutral water $^{3}$ & $\mathrm{WW}$ & $6.5(0.27)$ & $+877(12.2)$ & $51(2.0)$ \\
Tap water & $\mathrm{NW}$ & $7.0(0.07)$ & $+849(4.5)$ & $38(0.4)$ \\
\hline
\end{tabular}

Values in parenthesis indicate standard deviations.

${ }^{1}$ Test water prepared by SUPER WATER mini, Hirata (Osaka, Japan).

${ }^{2}$ Test water prepared by ACIDENT, J. Morita Tokyo MFG (Tokyo, Japan).

${ }^{3}$ Test water prepared by AP aqua21, Asahipretec Corp (Kobe, Japan). 
(a)

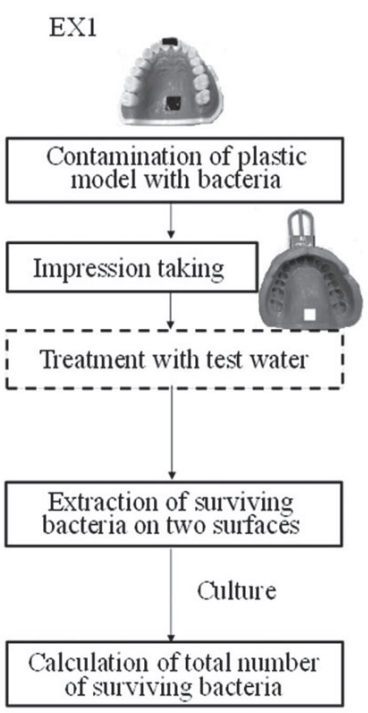

(b)

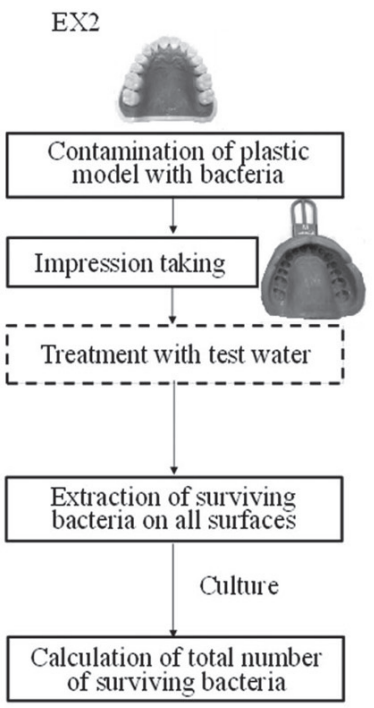

(c)

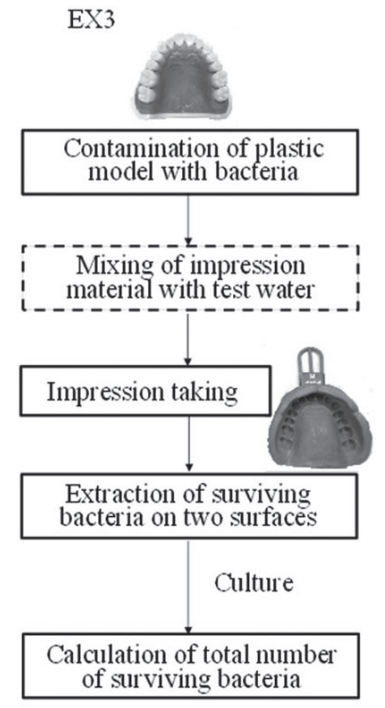

(d)

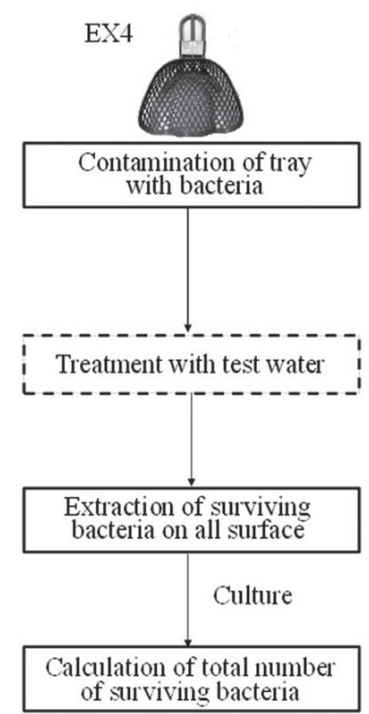

Fig. 1 Flow charts of four experiments of bactericidal activity.

(a) EX1: test for two surfaces of a predetermined area $\left(1 \mathrm{~cm}^{2}\right)$ on the impression. (b) EX2: test for all surface of the impression with tray. (c) EX3: test for all surface of the impression with tray when mixed with test water. (d) EX4: test for all surface of the tray.

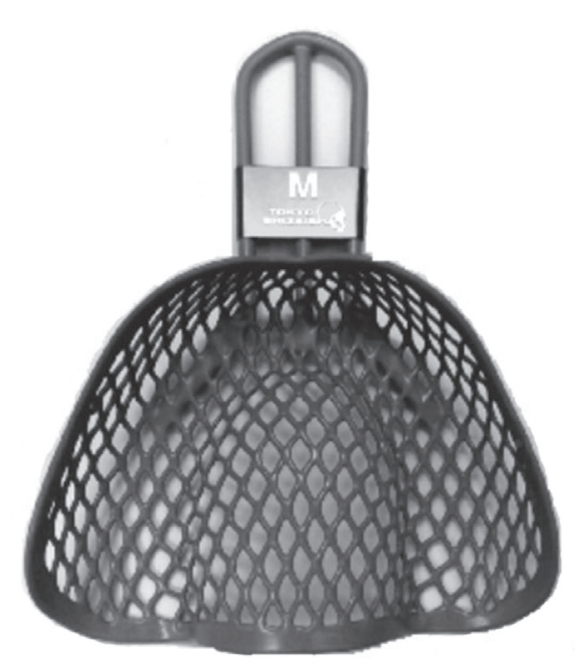

Fig. 2 Impression tray used in all the examination (EX14) in this study.

water as in EX1 was ultrasonically cleaned in $300 \mathrm{~mL}$ of sterile saline solution for $30 \mathrm{~s}$, and $0.1,1$ or $5 \mathrm{~mL}$ from the extract solution or its dilution, which was diluted with fresh sterile saline solution as needed, was added to the agar culturing medium (Nutrient Agar, Nissui Pharmaceurical). The total number of the surviving bacteria was calculated from the number of the colonies
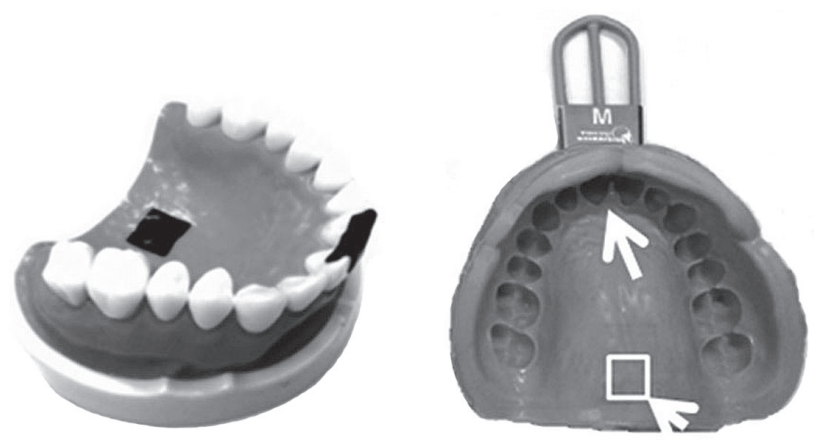

Fig. 3 Two areas sampled bacteria on the impression in EX1.

(They are equivalent to black parts on the model.)

in the medium after incubation at $37^{\circ} \mathrm{C}$ for $24 \mathrm{~h}$. As a control, the number of bacteria attached to an untreated impression was also similarly examined. In the case showing no colony formation, the impression with tray treated with the test water was immersed in $300 \mathrm{~mL}$ of $\mathrm{BHI}$ at $37^{\circ} \mathrm{C}$ for $48 \mathrm{~h}$. It was considered that the surviving bacteria were not detected all over the surface if BHI was still clear after immersion.

In Ex3 shown in Fig. 1(c), the bactericidal activity of the test water when used for mixing of the alginate impression material was also evaluated. An impression of the plastic model contaminated with bacteria was 


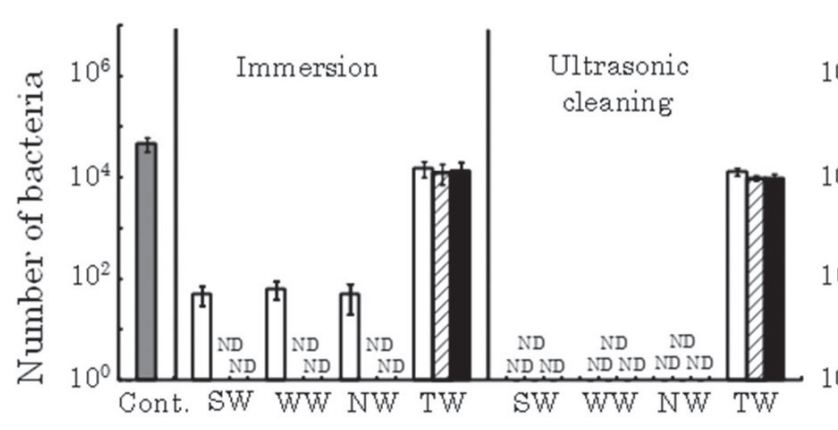

Palate

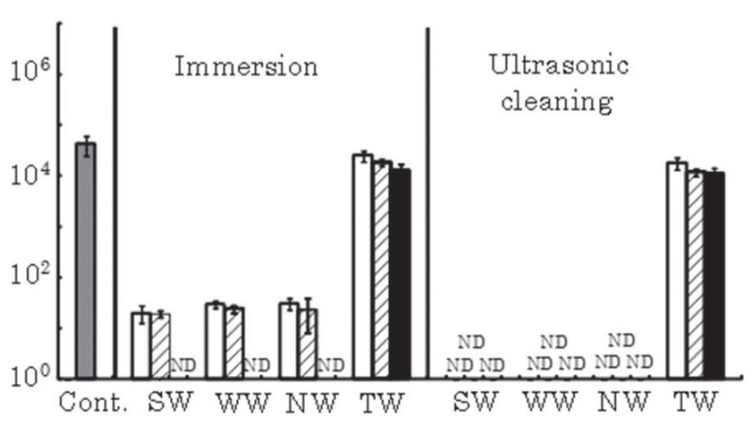

Anterior edge

\section{: control (without treatment) \\ $\mathrm{ND}$ : no surviving bacteria were detected}

Fig. 4 Number of surviving bacteria on a part of impression $\left(1 \mathrm{~cm}^{2}\right)$ after treatment in test water examined in EX1.

taken with the mixture of the alginate impression powder and the test water. After the impression taking, it was not treated with test water. The total number of surviving bacteria on all the surfaces of the impression with tray was examined as in EX2.

Procedures of the experiment for the tray (EX4) are shown in Fig. 1(d). The impression tray was immersed in $300 \mathrm{~mL}$ bacteria suspension for $10 \mathrm{~min}$ and was lightly shaken to remove the suspension from its surface. The tray with its surface contaminated with the level of $10^{6}$ to $10^{7}$ bacteria was immersed in $500 \mathrm{~mL}$ of the test water with or without ultrasound. After treatment, the tray was ultrasonically cleaned in $300 \mathrm{~mL}$ of sterile saline solution for $30 \mathrm{~s}$ in order to extract the surviving bacteria, and 0.1 or $1 \mathrm{~mL}$ from the extract solution or its dilution, which diluted with fresh sterile saline solution as needed, was added to the agar culturing medium. The total number of the surviving bacteria was calculated from the number of the colonies in the medium after incubation at $37^{\circ} \mathrm{C}$ for $24 \mathrm{~h}$. As a control, the number of the bacteria attached to the tray without any disinfection treatment was also similarly examined. In the case showing no colony formation, the tray treated with the test water was immersed in $300 \mathrm{~mL}$ of BHI at $37^{\circ} \mathrm{C}$ for 48 h. It was considered that the surviving bacteria were not detected all over the surface of the tray after treatment if BHI was still clear after immersion.

\section{Statistical analysis}

All the experiments were repeated 3 times at $23 \pm 2{ }^{\circ} \mathrm{C}$ and the results were statistically compared by one-way analysis of variance (ANOVA) and Bonferroni/Dunn post hoc test at a level of $p=0.05$ or 0.01 .

\section{RESULTS}

\section{Bactericidal effect on alginate impression}

The numbers of the surviving bacteria on two areas of the impression, the palate and the anterior edge, after immersion and ultrasonic cleaning in the test water, which was examined in EX1, are shown in Fig. 4 with a logarithmic scale. "Ultrasonic cleaning" in this figure means the immersion with ultrasound; the same shall apply in the following figures. There was no difference in the bacteria shifted from the plastic model to the impression between the areas tested and about $4.5 \times 10^{4}$ bacteria were detected on each area $(p>0.05)$. After 5 -min immersion in TW even if added ultrasonic action, about $10^{4}$ bacteria were still detected on the surface of each area. No significant differences in the number of bacteria remaining on the surface of impression were found between both areas in TW $(p>0.05)$. On the other hand, the number of the surviving bacteria still remaining on these areas of the impression decreased to the level of $10^{1}$ after 1-min immersion in any electrolyzed water, $\mathrm{NW}$ and the other two types. In both areas, there were no significant differences among the electrolyzed waters used $(p>0.05)$. None of the bacteria remained at each area on impression, the palate after 3 - and the anterior edge after 5-min immersions, without ultrasound in any electrolyzed water. Only 1-min treatment in these electrolyzed waters could disinfect the surface of the impression by addition of ultrasonic cleaning.

The numbers of the surviving bacteria on all the surface of impression with the tray after immersion and ultrasonic cleaning in the test water, which were examined in EX2, are shown in Fig. 5. The bacteria shifted from the plastic model to the impression were at the level of $10^{6}$. Immersion in TW showed a slight decrease in the number of surviving bacteria. However, about $5 \times 10^{5}$ bacteria still remained on the impression with the tray after 5-min immersion. Even if addition of ultrasonic cleaning, the number of surviving bacteria on it was the same level $\left(10^{5}\right)$. In contrast, the number of the surviving bacteria still remaining on the impression with tray decreased sharply to the level of $10^{2}$ after 1 - 


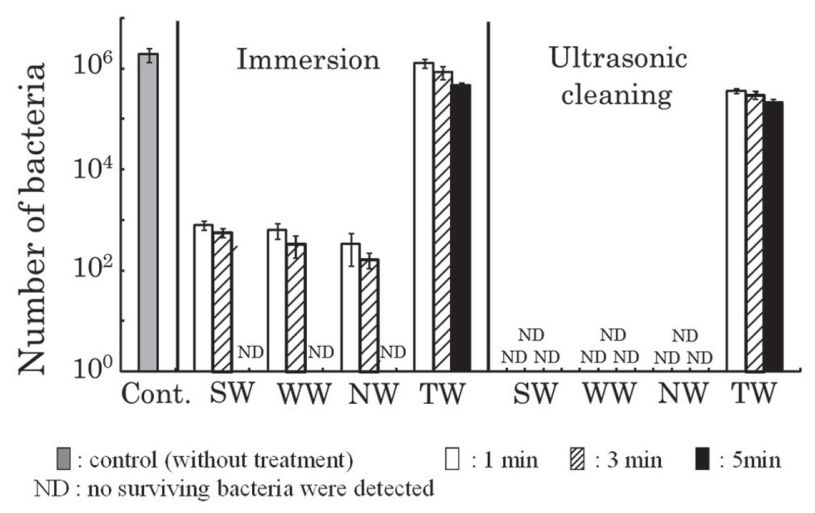

Fig. 5 Number of surviving bacteria on impression with tray after treatment in test water examined in EX2.

and 3-min immersions in NW and the other two types. In these 1- and 3-min immersions, NW showed larger effect of decreasing the bacteria on the impression than SW $(p<0.05)$. None of the bacteria remained on the impression with the tray by 5 -min immersion without ultrasound in any electrolyzed water. Only 1-min treatment in these electrolyzed waters, NW and the other two types, could disinfect all the surface of the alginate impression with the tray by addition of ultrasonic cleaning.

\section{Bactericidal effect on alginate impression mixed with test water}

The numbers of the surviving bacteria on the impression with tray when the test water was used for mixing with impression powder instead of the tap water (TW) are shown in Fig. 6. After taking the impression of a contaminated plastic model and removing, the level of $10^{6}$ of surviving bacteria were observed on the impression with tray for all mixing waters used. No bactericidal effects of NW were observed like those of SW and WW when used as mixing water. There were no significant differences in the number of bacteria remaining on the surface of impression among four test waters, TW and three electrolyzed waters $(p>0.05)$.

\section{Bactericidal effect on impression tray}

Figure 7 shows the numbers of the surviving bacteria on the impression tray after immersion and ultrasonic cleaning in the test water which were examined in EX4. The bacteria shifted from the bacteria solution to the impression tray were at the level of $10^{6}$ to $10^{7}$. The number of the surviving bacteria on all the surface of the tray slightly decreased by 1-min immersion in TW; however, $2.8 \times 10^{6}$ bacteria still remained on it. There was no significant difference in the number of the surviving bacteria between 1 - and 5 -min immersions $(p>0.05)$. Ultrasonic cleaning in TW showed significant additional effects of removing the surviving bacteria from the impression $(p<0.01)$. However, $1.4 \times 10^{5}$ bacteria remained on it even if treatment time was extended to

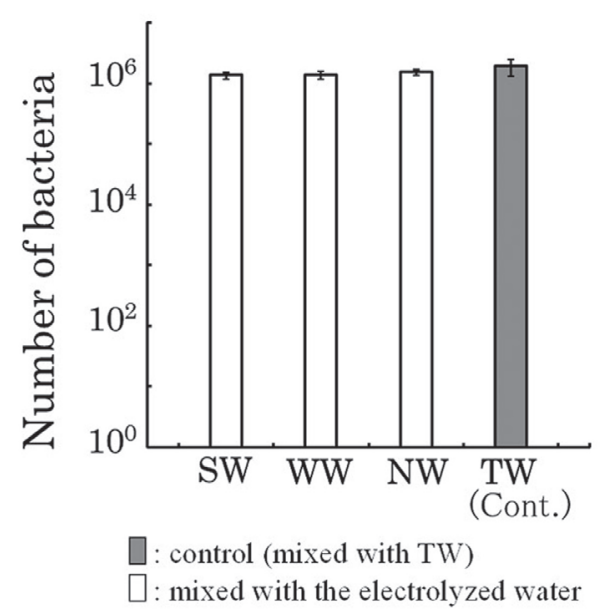

Fig. 6 Number of surviving bacteria on impression with tray when the impression material was mixed with the test water examined in EX3.

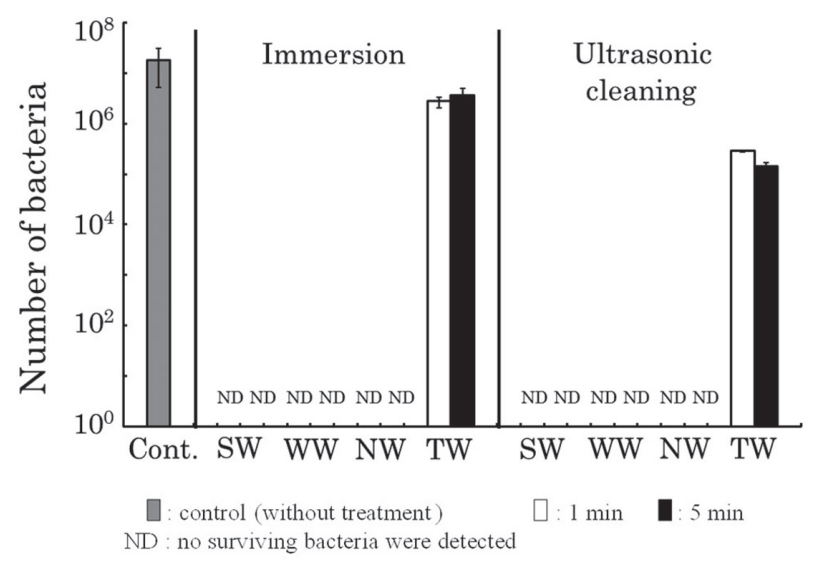

Fig. 7 Number of surviving bacteria on impression tray after treatment in test water in examined in EX4.

5 min. Conversely, none of the bacteria could survive on the surface of the tray after only 1-min immersion in any electrolyzed water tested, NW and the other two types. No significant bactericidal effects were found among the three electrolyzed waters tested $(p>0.05)$.

\section{DISCUSSION}

The electrolyzed water, which is one of the functional water composed of hypochlorous acid $(\mathrm{HClO})$ as a principal component for sterilization, has attracted great attention of its excellent bactericidal and virucidal activities since strong acid type was first developed in 1987. Weak acid, slight acid and neutral types of waters were developed later. These various electrolyzed waters show the individual $\mathrm{pH}$ and ORP values by different producing processes such as electrolysis with or without 
diaphragm, electrolyte and raw water. The changes in $\mathrm{pH}$ would affect the amount of $\mathrm{HClO}$ which has the strongest bactericidal activity among the residual chlorine ${ }^{28)}$. Hotta et al. ${ }^{29)}$ reported that sterilization effects of electrolyzed water with $40 \mathrm{ppm}$ of residual chlorine were equal to or stronger than those of 1,000 $\mathrm{ppm}$ of Sodium Chlorine $(\mathrm{NaClO})$ solution. Recently, another type of electrolyzed water containing high concentration of residual chlorine, $600 \mathrm{ppm}$, which is much higher than the conventional types (10-80 ppm), was developed and has been used as an electrolyzed water in clinical endodontology ${ }^{30}$ and in periodontal treatment ${ }^{31}$. Maki et al..$^{32)}$ recently reported that 5-20 min immersion in this high concentration type (diluted to $400 \mathrm{ppm}$ ) showed sufficient bactericidal activity without affecting the surface of stone casts by the examination using impressions removed from mouths. Although a simple comparison with waters used in this study is impossible, it requires too longer immersion and seems not to reflect the characteristic excellent bactericidal activity of electrolyzed water.

In the previous study ${ }^{21}$ in which the bactericidal effect of SW was examined on impression of bacteriacontaminated flat surface of cylindrical model, $4 \times 10^{5}$ bacteria attached to the alginate impression were completely sterilized by only 1-min immersion in SW. Another study ${ }^{33)}$ examining disinfection of dental instruments demonstrated that the complicated configuration required longer time of ultrasonic cleaning in SW indicating some difficulty in sterilizing the concave. As the practical impression has complicated concave and convex surfaces, 1-min immersion may be quite insufficient for complete disinfection of impression in clinical use.

In the present study, therefore, the bactericidal effects of electrolyzed water were examined using alginate impression of bacteria-contaminated maxillary dental arch model approximating dental practice. In the palate area, it was found that a small number of bacteria remained on the impression after 1-min immersion treatment in any electrolyzed water and they completely disappeared by immersion for 3 min or more. When the impression was ultrasonically cleaned in SW, WW or NW, no bacteria were detected by only 1-min treatment.

In the anterior edge area with deep concave, it was necessary to immerse the impression in any electrolyzed water for $5 \mathrm{~min}$ for complete disinfection while no remaining bacteria were observed after only 1-min ultrasonic cleaning. No significant effects of ultrasonic cleaning in TW were found on removal of bacteria when compared with immersion treatment in both areas of the palate and anterior edge. It suggests that the fluid streams to the contact surface created by the ultrasonic waves increased the bactericidal reaction with the fresh electrolyzed water and amplified the bactericidal effect, rather than a mechanical attack peeling off the attached bacteria.

Although the metallic ready-made tray has a complicated configuration of coarse net structure for tightly holding alginate impression, no surviving bacteria were detected on the tray after only 1-min immersion in any electrolyzed water. It might be because the bacteria could not invade the inside of the tray and any electrolyzed water could make complete contact with the overall bacteria-contaminated but smooth surfaces.

As a whole of the alginate impression containing tray, the electrolyzed water showed marked bactericidal effect in which the surviving bacteria completely disappeared after 5-min immersion and only 1-min ultrasonic cleaning. Although the conventional disinfectant chemical solutions yielded serious distortion of dental arch stone cast due to prolonged immersion treatment of the alginate impression, it is expected that all the electrolyzed waters used in this study will not cause detectable distortion of the cast because the disinfection treatment is completed in a short time as previously shown for $\mathrm{SW}^{18)}$.

The present study also examined whether such an excellent bactericidal effects of the electrolyzed waters would be exerted when they were directly used for mixing the alginate impression material instead of tap water. As already shown in the previously report ${ }^{21}$, no practical effect of this usage was found in SW. The residual chlorine might most contribute to the bactericidal effect and it might be rapidly consumed by contact with organic matter in the material to cause the decline and disappearance of the bactericidal effect. In WW and NW having much higher durability of bactericidal activity than SW ${ }^{19)}$, no decreased number of bacteria were also found on the surface of the alginate impression with the use for mixing contrarily to expectation. It might be the reason why the residual chlorine immediately decreased and disappeared by contact with the impression material in mixing that the amount of the electrolyzed water against the alginate impression powder (standard $\mathrm{w} / \mathrm{p}$ ratio) was too smaller than in the usual immersion or washing treatment. High hydrophilicity of alginate impression often causes the invasion of pathogenic microorganisms into its inside. The authors previously reported that the alginate impression showed much larger number of bacteria on its surface than the silicone rubber when the impression was taken of the bacteriacontaminated original model and the bacteria were also observed within the inside to the depth of $0.1-3.0 \mathrm{~mm}$ in the alginate impression ${ }^{21}$. It also reported that almost all the bacteria were observed within the inside to the depth of $0-1 \mathrm{~mm}^{21}$. Hosoda ${ }^{34)}$ reported that the blood invaded into the depth of $0.7-2 \mathrm{~mm}$ from the surface of alginate impression. As the electrolyzed water, however, could penetrate the alginate impression bulk to the depth of $0.62-0.99 \mathrm{~mm}$ by ultrasonic cleaning for $1-10 \mathrm{~min}^{21}$, it may be possible to expect its potential to disinfect even the subsurface of impression.

As shown in the results, SW, WW and NW were equally useful for disinfection of alginate impression in extremely short time. Furthermore, their waste liquids have no risk of contaminating drainage canal with chemicals because they revert to plain water with elapse of time. In addition to these common merits, each type of 
water has positive individual characteristics. Nishimura et $a l .{ }^{35)}$ reported that the disinfection effects of strong acid electrolyzed water were improved by combined use with the alkaline water which was a by-product at the electrolyzation. It was considered that the solubilization of the organic matter by surface activity of $\mathrm{OH}^{-}$in the alkaline water might induce the effective washing treatment before disinfection in the strong acid water. SW, strong acid water used in the present study, is also produced by electrolyzation of sodium chloride aqueous solution with the same amount of strong alkaline water and the disinfection effect may be accelerated if pre-immersion in this alkaline water is added to the treatment. In contrast, the slight acid water, WW, is produced without by-product of alkaline water. In the case of neutral electrolyzed water, NW, the amount of alkaline water by-produced is quite less than NW itself and not sufficient to be used for pre-immersion just after production. Thus, both WW and NW were impossible to rely on the pre-treatment with alkaline water.

The largest disadvantages of strong acid water are the severe corrosiveness to metals and erosiveness to dental hard tissues due to its low $\mathrm{pH}$ value. Many types of dental alloys and piping alloys were markedly corroded $^{36)}$ and enamel was tremendously eroded in $\mathrm{SW}^{24)}$. The corrosive and erosive properties significantly decreased as the $\mathrm{pH}$ value increased, and WW was much less corrosive and erosive than SW and NW caused no or very little corrosion and erosion similarly to tap water ${ }^{37)}$.

The surface of the metallic tray used for alginate impression in present study is covered with nylon resin. The resin layer will peel off and the metal surface will be exposed to corroding environments like other metal tray not covered with resin by repeated treatments of impression taking, disinfection and autoclaving. Although the corrosion of the tray may cause no actual harm to patients, it is desirable to protect it from corrosion if at all possible.

NW is neutral and mildest against not only metals and but also oral tissues like tap water among the electrolyzed water as shown by its clinical usefulness in dentistry such as in hemostasis ${ }^{38)}$, disinfection of denture $^{33)}$ and cleaning of pulp canal in endodontics ${ }^{26)}$. The foregoing circumstances suggest that the electrolyzed waters, above all the neutral water, may be the most appropriate for the disinfection of alginate impressions.

\section{ACKNOWLEDGMENTS}

The authors express great gratitude to Dr. Hiroshi KAKIGAWA and late Dr. Kiyoshi TAJIMA who were former members of the staff of Division of Biomaterials of Kyushu Dental University for their continuous assistances.

\section{REFERENCES}

1) Fujiwara K, Kusumoto H, Arakawa M, Tanaka M. Footsteps of Kiyoukai in research and application of strongly acidic electrolyzed water. J Funct Water 2014; 9: 9-13.

2) Iwasawa A. Handbook for flexible gastrointestinal endoscope reprocessor by funct water: its significance and assignments. J Funct Water 2014; 9: 15-21.

3) Iwasawa A, Furuta M, Kanno M, Mokudai T, Kohno M, Niwano Y. Washing and disinfection efficacy of the endoscope disinfection device CM-5. J Funct Water 2011; 6: 15-25.

4) Maillard JY. Antimicrobial biocides in the healthcare environment: efficacy, usage, policies, and perceived problems. Ther Clin Risk Manag 2005; 4: 307-320.

5) Taguchi M. Disinfection of impression. Dent Outlook 1995; 85: 865-874.

6) Shiba A. Application of electrolyzed water for hospital infection. J Showa Univ Dent Soc 1999; 19: 399-409.

7) Nokubi T, Ikebe K, Mitta K. Problems of denture cleaning and management in the elderly for infection protection. J Jpn Prosthodont Soc 1999; 43: 659-665.

8) Fukuta O. Infection control in the dental clinic of U.S.A.: a case of university of California, San Francisco. Dent Outlook 1993; 81: 1139-1147.

9) Nakamura Y. Prosthetic treatment and protection of the infectious disease. Forefront of disinfection. (ed. By Sato T, Shiiki K, Taguchi M). Tokyo, Dental Diamond, 1992, p.126131.

10) Nakamoto K, Tamamoto M, Hamada T. Survey for crossinfection control on alginate impression materials. $J$ Hiroshima Univ Dent Soc 1994; 26: 144-149.

11) Shima T, Fujihara A. Research on the actual condition about the infection prevention countermeasure in dentistry clinical. J J Dent Prac Admin 2003; 38: 144-148.

12) Motegi N, Kurehashi M, Ikegami Y, Momoi Y, Kawato F, Shimakura Y. Questionnaire of infection control procedures in dental clinics. J J Envi Infect 2010; 25: 302-309.

13) Kohn WG, Harte JA, Malvitz DM, Collins AS, Cleveland JL, Eklund KJ. Centers for disease control and prevention: Guidelines for infection control in dental health care settings 2003. J Am Dent Assoc 2004; 135: 33-47.

14) The Japan Prosthodontic Society. A guideline for infection control protocol in prosthodontic practice. Ann Jpn Prosthodont Soc 2007; 51: 627-689.

15) Yamanaka M, Nomasa H, Yokoyama Y, Tajima K, Kakigawa $\mathrm{H}$, Kozono Y. Dimensional change of alginate impression by storing part.1 dimension of dental arch model. J Kyushu Dent Soc 1990; 44: 757-763.

16) Obata N. Application of electrolyzed water to washing system. J Toyama Univ Int Stud 2004; 4: 121-123.

17) Yamamoto M, Yamada M. Effect of pasteurization for raw vegetables by acidic electrolysis water. J Wayo Women's Univ 1999; 39: 27-34.

18) Hricova D, Stephan R, Zweifel C. Electrolyzed water and its application in the food industry. J Food Prot 2008; 71: 19341947.

19) Arai I, Senda A, Yamagami K, Muryoya A, Nakamura T, Urashima T. Efficacy of acidic electrolyzed water for premilking teat cleaning and disinfection. Hokkaido $\mathrm{J}$ Livestock Grassland Sci 2002; 44: 59-63.

20) Shiba A, Shiba K: Handbook of acidic electrolyzed water, Tokyo, Igaku Joho-sha, 1995. p.2-143.

21) Nagamatsu Y. Sterilization of impression with electrolyzed acid water. J Kyushu Dent Soc 1996; 50: 515-531.

22) Yamanaka M, Nagamatsu Y, Kakigawa H. Effects of immersion sterilization on alginate impression —compatibility of electrolyzed acid water-. J Kyushu Dent Soc 1997; 51: 73783.

23) Nagamatsu Y, Chen KK, Tajima K, Kakigawa H, Kozono Y. Durability of bactericidal activity in electrolyzed neutral water by storage. Dent Mater J 2002; 1: 93-104.

24) Nagamatsu Y, Chen KK, Kita N, Tajima K, Kakigawa H, Kozono Y. Application of electrolyzed neutral water to dental 
practice —effects on human enamel surface-. J J Dent Mater 2008; 27: 283-290.

25) Taniguchi M, Nagamatsu Y, Yamanaka M, Kakigawa H, Kozono Y. Sterilization of denture with electrolyzed neutral water. J Kyushu Dent Soc 2008; 62: 29-38.

26) Kita N, Nagamatsu Y, Chen KK, Tajima K, Kakigawa H, Kozono Y. Application of electrolyzed neutral to root canal irrigator. J Kyushu Dent Soc 2009; 63: 44-56.

27) Kozono Y. Usefulness of sterilization with electrolyzed neutral water. DE 2007; 160: 32-34.

28) Molinari JA, Cottone JA. Infection control in dentistry: update for the 1990's. Clin Dent 1994; 1: 1-11.

29) Hotta K, Komiyama K, Nakayama T, Kogure M, Kikuchi K. Hypochlorous acid water: Approval electrolytic principle, kind, physic-chemical property, effectiveness, safety, remarks on effective use. J Funct Water 2012; 8: 1-8.

30) Nakamura Y, Sekine K, Takahashi T. Utilization of electrolyzed functional water in clinical endodontology. $\mathrm{J} \mathrm{J}$ Dent Mater 2011; 30: 9-12.

31) Takeuchi Y, Izumi Y. Application of neutral electrolyzed functional water for periodontal treatment. J J Dent Mater 2011; 30: 13-16.

32) Maki S, Hamasaka H, Matsui A, Okawa Y, Somekawa S, Endo
M, Amano S, Hibino Y, Okamoto K, Ohmori Y, Nakajima H, Ohkawa S. A study on the disinfection of alginate impressions using hypochlorous-acid electrolyzed water. J Meikai Dent Med 2015; 44: 36-49.

33) Nomasa H, Nagamatsu Y, Tajima K. Sterilization of dental instruments by electrolyzed water and their corrosion behaviors. J Kyushu Dent Soc 1997; 51: 784-799.

34) Hosoda H. Decontamination and prevention of cross-infection in dental clinics. J A Dent Sci 1991; 10: 42-55.

35) Nishimura A, Tsukasaki H, Shiba A, Kanaishi A, Kase C, Niinomi K, Nishimura S. The sterilization and disinfection effect of alginate impression material by using electrolyzed water. J Funct Water 2003; 2: 23-27.

36) Murakami S, Nagamatsu Y, Chen KK, Tajima K, Kakigawa H, Hosokawa R, Kozono Y. Corrosion behavior of water pipe metals in electrolyzed water. International Dental Materials Congress 2007, Nov 21-24; Bangkok, Thailand, 2007, p.294.

37) Dong H, Nagamatsu Y, Chen KK, Tajima K, Kakigawa H, Shi $\mathrm{S}$, Kozono Y. Corrosion behavior of dental alloys in various types of electrolyzed water. Dent Mater J 2003; 22: 482-493.

38) Koga Y, Osumi T, Higashi S, Osumi T, Kuroki K, Kozono Y. Local hemostatic effect of electrolyzed neutral water in wound surface of mice tail. J Kyushu Dent Soc 2004; 58: 51-56. 